\title{
Characteristics of mature wheat embryos with different resistance to scab cultured in vitro with Fusarium graminearum crude toxin
}

\author{
S. Wang ${ }^{1}$, M. Wang ${ }^{1}$ and C.Y. Zhang ${ }^{2}$ \\ ${ }^{1}$ School of Agronomy, Anhui Agricultural University, \\ Anhui Provincial Key Laboratory of Wheat Biology and Genetic Improvement on \\ South Yellow \& Huai River Valley, Ministry of Agriculture, Hefei, Anhui, China \\ ${ }^{2}$ Anhui Science and Technology University, Fengyang, Anhui, China \\ Corresponding author: M. Wang \\ E-mail: wangminvip2@126.com
}

Genet. Mol. Res. 14 (4): 17348-17357 (2015)

Received September 29, 2015

Accepted November 10, 2015

Published December 21, 2015

DOI http://dx.doi.org/10.4238/2015.December.21.3

\begin{abstract}
Five wheat varieties with different resistance to scab were used to study the effect of Fusarium graminearum crude toxin on culture characteristics of mature wheat embryos in vitro. The results showed that the rate of induction and differentiation of mature embryo callus differed significantly between varieties, toxin concentration, and concentration $x$ varieties. Alow concentration ( $5 \mathrm{~g} / \mathrm{L}$ ) of $F$. graminearum crude toxin promoted callus formation in very resistant varieties, while high concentrations (10 and $15 \mathrm{~g} / \mathrm{L}$ ) hindered it, i.e., the higher the concentration, the stronger the inhibition. The rate of induction and differentiation of mature embryo callus decreased with increasing concentration of $F$. graminearum crude toxin, thus the lower the resistance, the lower the differentiation. At $10 \mathrm{~g} / \mathrm{L}$ toxin, superoxide dismutase (SOD) activity of all five varieties was greater than that of the control group $(0 \mathrm{~g} / \mathrm{L})$. At $20 \mathrm{~g} / \mathrm{L}$ toxin, SOD activity of the five varieties declined; only two resistant varieties, Sumai 3 and Zheng 9023, still showed higher levels than the control, while the three susceptible
\end{abstract}


varieties had lower levels than the control. Therefore, there was a relationship between SOD activity and scab resistance in wheat varieties.

Key words: Wheat mature embryo; Fusarium graminearum crude toxin; In vitro culture; Callus; Superoxide dismutose

\section{INTRODUCTION}

Scab is an important disease of wheat, mainly caused by Fusarium graminearum (Lu et al., 2011). F. graminearum infected spikes lead to a decline in yields of wheat, grain quality deterioration and production of mycotoxins, which are toxic to humans and animals. Wheat scab resistance is a quantitative trait of polygenic inheritance (Song et al., 2005), and few resistant varieties have been obtained using traditional breeding methods. The response of wheat to F. graminearum toxin varies with genotype; there is a significant positive correlation between scab resistance and resistance to F. graminearum toxin (Wang et al., 1999; Liu et al., 1999; Han et al., 2003). According to this correlation, mutation screening for anti-scab wheat has made some progress by in vitro culture of wheat tissue with F. graminearum toxin. Yan et al. (1995) screened Xiannong 151, Shaanxi 167, Shaan 229 and other cell varieties (lines) of anti- $F$. graminearum toxin by inflorescence callus culture. Wu et al. (1994) obtained some plants with a better resistance in the field compared to the original donor variety from cell lines with resistance (tolerance) to F. graminearum toxin using immature spikes and immature embryo callus (Wu et al., 1994). Zhang et al. (2006) studied the effects of embryo development time and F. graminearum crude toxin on wheat callus induction and plantlet differentiation. In tissue culture of wheat, immature embryos are recognized as the best explants, and investigators generally choose immature embryos for vivo culture, due to their high induction to callus and strong plant regeneration ability. But the preparation of young spikes and young embryos is limited by times and seasons, while mature wheat embryos can be stored for long periods and would be readily available, facilitating the use of test subjects and accelerating studies. In this paper, five wheat varieties with different resistance to scab were used to study the effect of F. graminearum crude toxin on culture characteristics of mature wheat embryos in vitro, to provide a theoretical reference for the establishment of scab-resistant germplasm screening and identification system and screening of scab-resistant wheat by cell clone.

\section{MATERIAL AND METHODS}

\section{Subjects}

The subjects were five wheat varieties with different resistance to scab: Sumai 3 (high resistance), Zheng 9023 (medium resistance), Ligao 6 (susceptible), Wanmai 47 (susceptible) and Wanmai 19 (susceptible).

\section{Isolation of $\boldsymbol{F}$. graminearum crude toxin}

F. graminearum crude toxin was isolated by the method of Liu et al. (1997) Wheat grains infected by Gibberella were ground and dried at $70^{\circ} \mathrm{C}$, and $100 \mathrm{~g}$ dry powder were treated with $75 \%$ alcohol three times (first with $400 \mathrm{~mL}$ and then $300 \mathrm{~mL}$ twice) and separately soaked for 24 $\mathrm{h}$, with shaking during soaking. After being filtered with double gauze, the residue was extruded 
and eventually discarded. The filtrate was placed in a $1000-\mathrm{mL}$ beaker and concentrated to a concentration of $0.8-1 \mathrm{~g}$ (dry powder) $/ \mathrm{mL}$ in a $60^{\circ} \mathrm{C}$ water bath. Finally, the dry powder was dissolved to $0.5 \mathrm{~g} / \mathrm{mL}$.

\section{Preparation of the medium}

Induction medium consisted of MS, $0.5 \mathrm{~g} / \mathrm{L}$ hydrolyzed lactalbumin, $4 \mathrm{mg} / \mathrm{L} \mathrm{2,4-D,} 30$ $\mathrm{g} / \mathrm{L}$ sucrose and $0.45 \%$ agar, $\mathrm{pH}$ 5.8. Differentiation medium contained MS, $0.5 \mathrm{~g} / \mathrm{L}$ hydrolyzed lactalbumin, $1 \mathrm{mg} / \mathrm{L} \mathrm{KT,} 1.5 \mathrm{mg} / \mathrm{L} \mathrm{IAA}, 30 \mathrm{~g} / \mathrm{L}$ sucrose and $0.45 \%$ agar, $\mathrm{pH} 5.8$. Different amounts of $F$. graminearum crude toxin were added to the two media, at concentrations of $0(\mathrm{CK}), 5,10$ and $15 \mathrm{~g} / \mathrm{L}$.

\section{Culture method}

Uniform and plump wheat seeds were washed with water several times, and successively soaked in $75 \%$ alcohol for $5 \mathrm{~min}$ and $0.1 \% \mathrm{HgCl}_{2}$ for $25 \mathrm{~min}$, and then they were washed with sterile water 5 or 6 times before being soaked in sterile water for $18 \mathrm{~h}$. After soaking in $75 \%$ alcohol for 5 min on a clean bench, the seeds were sterilized in $0.1 \% \mathrm{HgCl}_{2}$ for $15 \mathrm{~min}$, washed with sterile water 5 or 6 times and drained before removing the mature embryos. Germ and radicle were starched for inoculation and seeded with the scutellum up. Each treatment was repeated seven times and 12 embryos were placed in one culture bottle. The inducing culture conditions were: $25^{\circ} \pm 1^{\circ} \mathrm{C}$ and $12 \mathrm{~h}$ light. Differentiation culture conditions were $25^{\circ} \pm 1^{\circ} \mathrm{C}$ and light intensity of $2000 \mathrm{~lx}$ for $16 \mathrm{~h}$.

\section{Superoxide dismutase (SOD) determination}

SOD was determined by the NBT photochemical reduction method of Zhang and Zhai (2003). SOD activity of mature embryos, 15-day callus, of five wheat varieties was determined after incubation with three concentrations of $F$. graminearum crude toxin $(0,10$ and $20 \mathrm{~g} / \mathrm{L})$. For enzyme assay, $0.5 \mathrm{~g}$ callus was ground in $1.5 \mathrm{~mL}$ PBS and washed $(1.25 \mathrm{~mL}$ PBS twice). The extract obtained was centrifuged at $15,000 \mathrm{rpm}$ for $15 \mathrm{~min}$ and the supernatant was diluted to $5 \mathrm{~mL}$. Enzyme activity was determined by mixing $2.5 \mathrm{~mL}$ methionine, $0.25 \mathrm{~mL}$ NBT, $0.15 \mathrm{~mL}$ riboflavin, $0.05 \mathrm{~mL}$ PBS and $0.05 \mathrm{~mL}$ extract. The $1 \mathrm{st}$ tube was the blank ( $3 \mathrm{~mL}$ PBS), and the $2 \mathrm{nd}$ tube was the test (all reagents including extract), while the 3rd tube indicated maximum photochemical reduction (all reagents but $0.01 \mathrm{~mL}$ PBS and no extract). Each tube was exposed to $4000 \mathrm{~lx}$ light for $20 \mathrm{~min}$, and absorbance was read at $560 \mathrm{~nm}$. SOD activity was calculated as follows:

$$
\text { SOD activity }=\frac{\left(A_{0}-A_{s}\right) \times V_{T}}{A_{0} \times 0.5 \times F W \times V_{1}}
$$

where: $A 0$ is the absorbance of the $3 r d$ tube; $A s$ is the absorbance of the $2 n d$ tube; $V_{T}$ is the total volume of sample $(\mathrm{mL}) ; V_{1}$ is the measured sample volume $(\mathrm{mL})$; and $\mathrm{FW}$ is the sample fresh weight $(0.5 \mathrm{~g})$. Increase in SOD activity $=$ [SOD activity $(10 \mathrm{~g} / \mathrm{L})$ - SOD activity $(0 \mathrm{~g} / \mathrm{L})] /$ SOD activity $(0 \mathrm{~g} / \mathrm{L})$.

\section{Statistical analysis}

After inoculation, callus formation and differentiation were observed every other day, and days of callus formation, number of calli produced, callus induction rate (\%), callus differentiation 
rate (\%) and callus mass ( $\mathrm{g}$ ) were recorded. The callus induction rate and callus differentiation rate are given as follows: callus induction rate $(\%)=$ (number of callus explants produced $/$ number of inoculated explants) $\times 100 \%$ and callus differentiation rate $(\%)=$ (number of calli with green spots $/$ number of inoculated calli) x 100\%. Statistical analysis was carried out using Excel and DPS.

\section{RESULTS}

\section{Variance analysis of callus induction rate and callus differentiation rate}

Variance analysis is shown in Table 1. The rate of induction and differentiation of mature embryo calli showed significant differences between varieties, toxin concentration and concentration $x$ varieties $(\alpha=0.01, F$ test $)$.

Table 1. Variation analysis for the callus induction and differentiation rate of mature embryo.

\begin{tabular}{|c|c|c|c|c|c|c|c|}
\hline \multirow[t]{2}{*}{ Source of variation } & \multirow[t]{2}{*}{ d.f. } & \multicolumn{3}{|c|}{ Induction rate } & \multicolumn{3}{|c|}{ Differentiation rate } \\
\hline & & SS & MS & $\mathrm{F}$ & SS & MS & $\mathrm{F}$ \\
\hline Concentration & 3 & $113,596.43$ & $37,865.48$ & $385.07^{\star *}$ & $105,500.00$ & $3,516.67$ & $292.48^{* *}$ \\
\hline Varietiy & 4 & $3,390.00$ & 847.50 & $8.62^{* *}$ & $3,575.71$ & 893.93 & $7.43^{* *}$ \\
\hline Concentration $\times$ varietiy & 12 & $3,992.86$ & 332.74 & $3.38^{* *}$ & $9,550.00$ & 795.83 & $6.62^{\star *}$ \\
\hline Error & 120 & $11,800.00$ & 98.33 & & $14,428.57$ & 120.24 & \\
\hline Total & 139 & $132,779.29$ & & & $133,054.29$ & & \\
\hline
\end{tabular}

**Means significant differences at 0.01 level.

\section{Induction and differentiation of mature embryo callus at different levels of toxin}

New multiple range test results for induction and differentiation rate of callus at four levels of toxin are shown in Table 2. There was a significant difference in callus induction rate between the four toxin concentrations $(P=0.01)$. Induction rate was $100 \%$ without toxin $(0 \mathrm{~g} / \mathrm{L})$ and gradually decreased with increasing concentration of toxin; callus induction rate was only $26.57 \%$ at $15 \mathrm{~g} / \mathrm{L}$ toxin. Callus differentiation rate also showed a significant difference with toxin concentration, where it decreased with increasing concentration of toxin, and callus differentiation rate was only $5.7 \%$ at $15 \mathrm{~g} / \mathrm{L}$ toxin, $71.2 \%$ lower compared with the no toxin group.

Table 2. Significant difference of callus induction and differentiation rate of mature embryo among toxin concentrations.

\begin{tabular}{|c|c|c|c|c|c|c|}
\hline \multirow[t]{3}{*}{ Concentration $(\mathrm{g} / \mathrm{L})$} & \multicolumn{3}{|c|}{ Induction rate } & \multicolumn{3}{|c|}{ Differentiation rate } \\
\hline & \multirow[t]{2}{*}{ Mean (\%) } & \multicolumn{2}{|c|}{ Significant difference } & \multirow[t]{2}{*}{ Mean (\%) } & \multicolumn{2}{|c|}{ Significant difference } \\
\hline & & 0.05 & 0.01 & & 0.05 & 0.01 \\
\hline 0 & 100 & a & $A$ & 76.90 & a & $A$ \\
\hline 5 & 91.14 & b & B & 43.10 & $b$ & $B$ \\
\hline 10 & 66.00 & c & C & 16.60 & c & C \\
\hline 15 & 26.57 & d & D & 5.70 & d & D \\
\hline
\end{tabular}

\section{Induction and differentiation of mature embryo callus in different varieties}

New multiple range test results for induction and differentiation rate of mature embryo callus of five wheat varieties are shown in Table 3. The induction rate of Sumai3 mature embryo 
callus was $77.50 \%$, which was the highest. There were significant differences compared with susceptible varieties Wanmai 47 and Wanmai $19(\alpha=0.05)$ and Ligao $6(\alpha=0.01)$; But there was no significant difference with Zheng 9023 with medium resistance.

Table 3. Significant difference of callus induction and differentiation rate of mature embryo among varieties.

\begin{tabular}{|c|c|c|c|c|c|c|c|}
\hline \multicolumn{4}{|c|}{ Induction rate } & \multicolumn{4}{|c|}{ Differentiation rate } \\
\hline \multirow[t]{2}{*}{ Varietiy } & \multirow[t]{2}{*}{ Mean (\%) } & \multicolumn{2}{|c|}{ Significant difference } & \multirow[t]{2}{*}{ Variety } & \multirow[t]{2}{*}{ Mean (\%) } & \multicolumn{2}{|c|}{ Significant difference } \\
\hline & & 0.05 & 0.01 & & & 0.05 & 0.01 \\
\hline Sumai 3 & 77.50 & a & A & Sumai 3 & 41.80 & $\mathrm{a}$ & A \\
\hline Zheng 9023 & 75.00 & $a b$ & $A B$ & Zheng 9023 & 41.40 & $\mathrm{a}$ & $A B$ \\
\hline Wanmai 47 & 71.07 & $\mathrm{~b}$ & $A B$ & Wanmai 19 & 33.60 & $\mathrm{~b}$ & B \\
\hline Wanmai 19 & 66.79 & $\mathrm{bc}$ & $\mathrm{B}$ & Wanmai 47 & 30.70 & $\mathrm{~b}$ & B \\
\hline Ligao 6 & 64.30 & $\mathrm{c}$ & B & Ligao 6 & 30.40 & $\mathrm{~b}$ & B \\
\hline
\end{tabular}

Figures 1 to 5 are the effects of different concentrations of F. graminearum crude toxin on the callus induction rate of different wheat varieties. The dynamic curve of the callus induction rate showed the following. At a toxin concentration of $5 \mathrm{~g} / \mathrm{L}$, callus formation of Sumai3 was faster than that at $0 \mathrm{~g} / \mathrm{L}$ from the 4 th to 12 th day. Callus formation of Zheng 9023 at $0 \mathrm{~g} / \mathrm{L}$ was faster than that at $0 \mathrm{~g} / \mathrm{L}$ from the 4th to 10th day. Callus formation of Ligao 6 at $0 \mathrm{~g} / \mathrm{L}$ was faster than that at $0 \mathrm{~g} / \mathrm{L}$ from the 4th to 6th day. Callus formation of Wanmai 47 at $0 \mathrm{~g} / \mathrm{L}$ was faster than that at $0 \mathrm{~g} / \mathrm{L}$ from the $2 \mathrm{nd}$ to 8 th day. Finally, callus formation of Wanmai 19 at $0 \mathrm{~g} / \mathrm{was}$ slower than that at $0 \mathrm{~g} / \mathrm{L}$. Thus, for some varieties, especially very resistant ones, low concentrations of toxin can accelerate the rate of callus formation from mature embryos. At toxin concentrations of 10 and $15 \mathrm{~g} / \mathrm{L}$, mature embryo callus formation of all five varieties was lower than that at $0 \mathrm{~g} / \mathrm{L}$. This showed that high concentrations of $F$. graminearum crude toxin had an inhibitory effect on callus formation, showing that the higher the concentration, the stronger the inhibition.

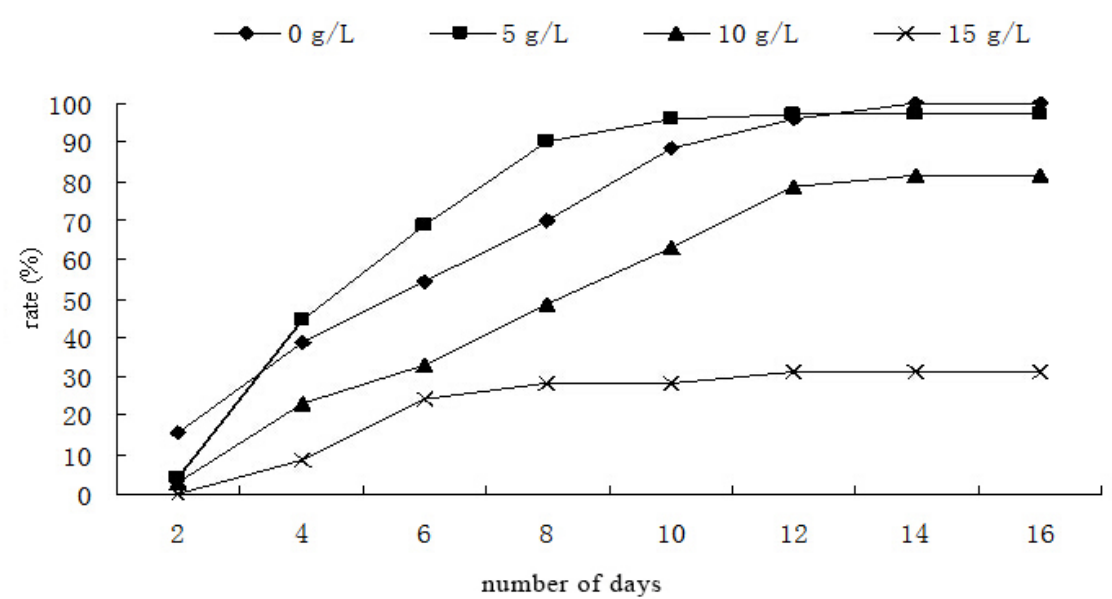

Figure 1. Callus induction of mature embryo of Sumai 3. 


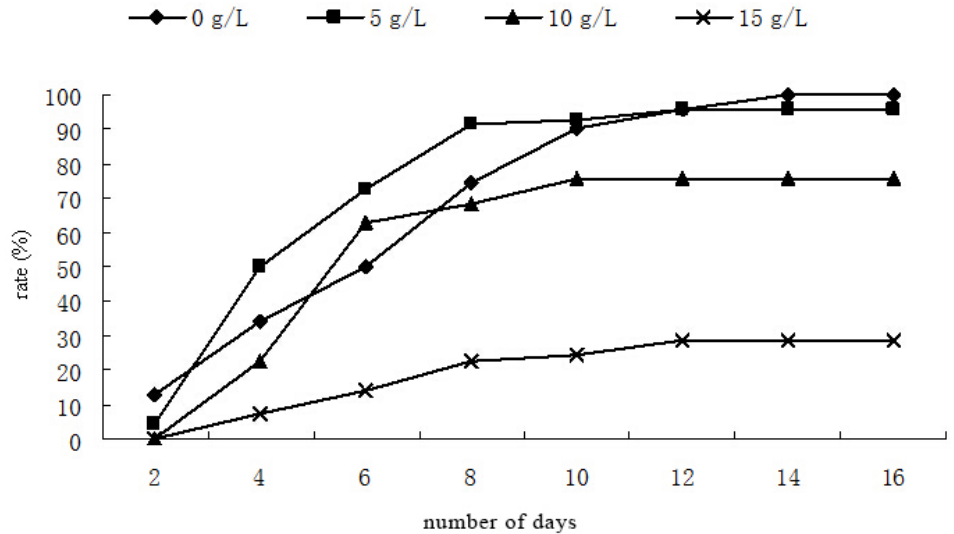

Figure 2. Callus induction of mature embryo of Zheng 9023.

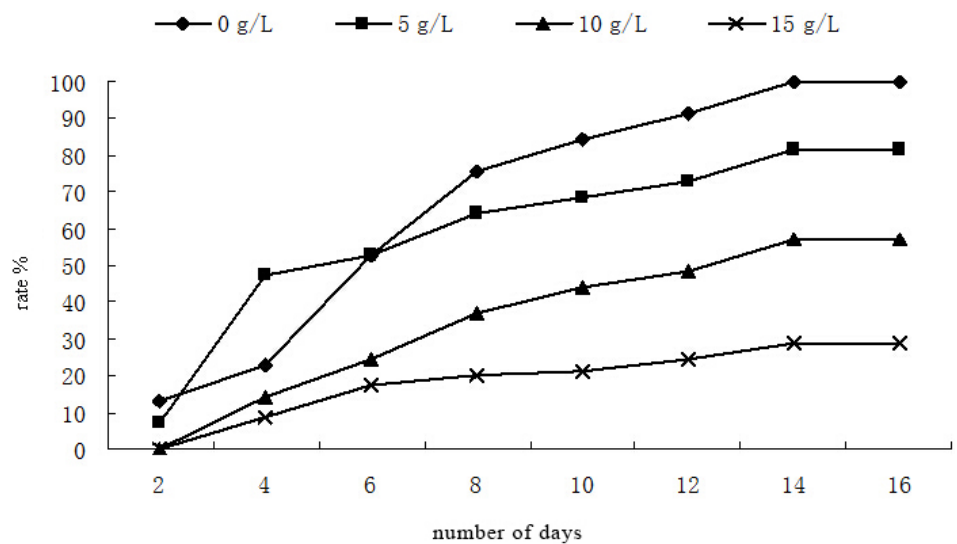

Figure 3. Callus induction of mature embryo of Ligao 6.

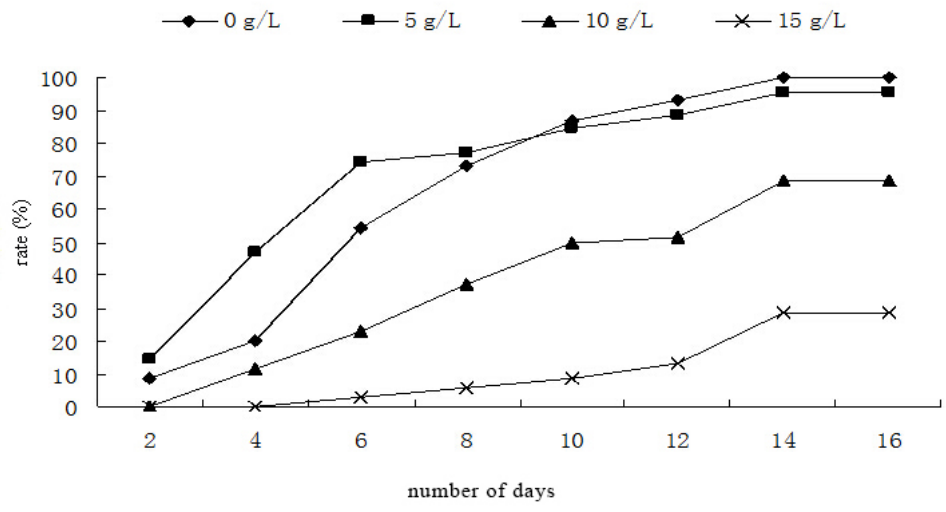

Figure 4. Callus induction of mature embryo of Wanmai 47. 


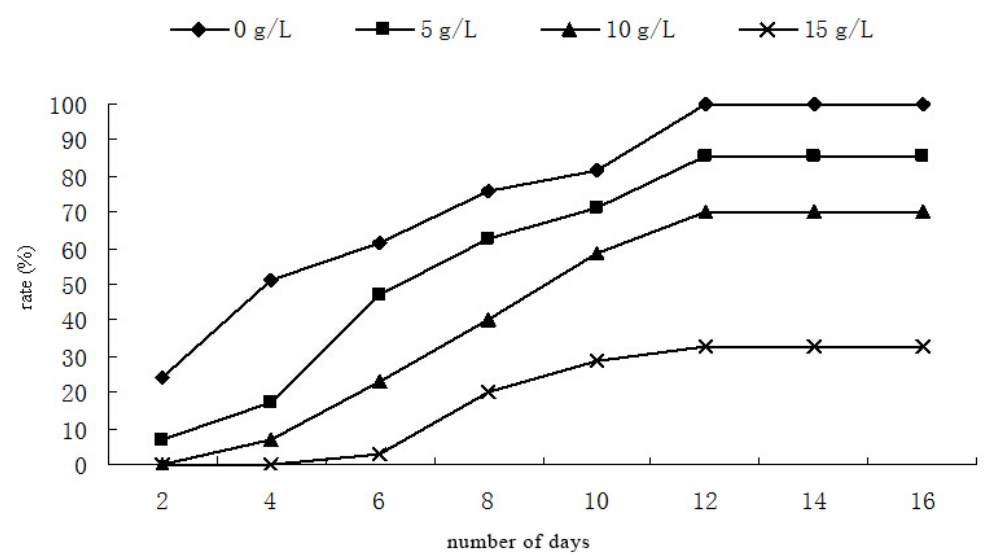

Figure 5. Callus induction of mature embryo of Wanmai 19.

In Table 3, Sumai3 had the highest callus differentiation rate (41.8\%), and there were significant differences compared with susceptible varieties Wanmai 47, Wanmai 19 and Ligao 6 $(\mathrm{a}=0.01)$, but there was no significant difference with Zheng 9023 with medium resistance. Zheng 9023 exhibited significant differences with Wanmai 47, Wanmai 19, and Ligao 6 at the level of 0.05 . Figure 6 showed the effects of different concentrations of toxin on callus differentiation rate of different wheat varieties. The higher the concentration of F. graminearum crude toxin was, the lower the differentiation rate was of callus from mature embryos. When the toxin concentration was $15 \mathrm{~g} / \mathrm{L}$, callus differentiation rate significantly decreased in all varieties: Sumai 3 by $15.71 \%$; Zheng 9023, Ligao 6 and Wanmai 47 and 19 were respectively 7.14, 2.86, 1.43 and 1.43\%. Compared with the control, they respectively decreased by 47.09, 68.57, 72.85, 82.86 and $84.28 \%$. When the toxin concentration was $0 \mathrm{~g} / \mathrm{L}$, the differentiation rate of Wanmai 47 and 19 was higher than that of Sumai 3, respectively exceeding 21.43 and $22.85 \%$. But at a concentration of $15 \mathrm{~g} / \mathrm{L}$, their differentiation rates were lower than that of Sumai 3, with a gap of $14.27 \%$. Thus, the rate of induction and differentiation of mature embryos callus decreased with increasing concentration of F. graminearum crude toxin.

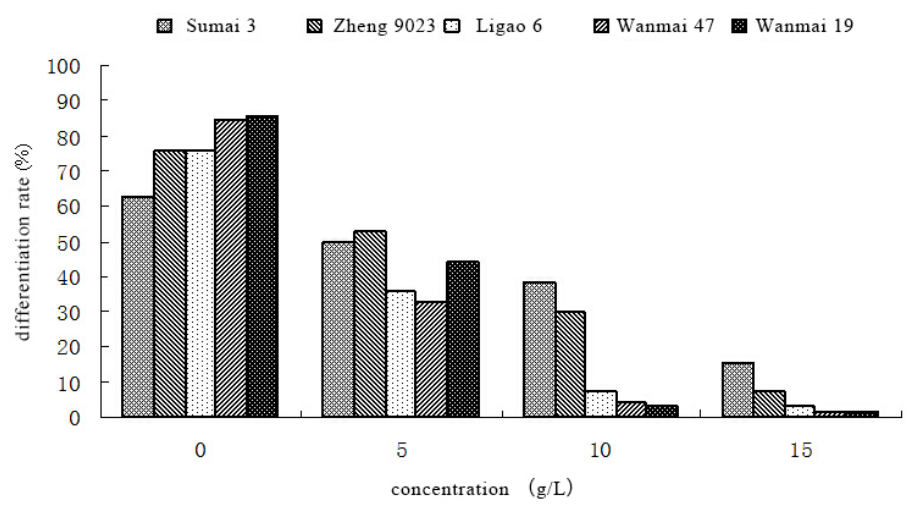

Figure 6. Effect of different concentrations of crude toxin on differentiation from mature embryo calli. 


\section{Effects of $F$. graminearum crude toxin on the quality of callus of wheat mature embryos}

Figure 7 showed the effects of different levels of $F$. graminearum crude toxin on the quality of callus from mature embryos of different wheat varieties. It showed that at the low concentration of toxin $(5 \mathrm{~g} / \mathrm{L})$, callus quality of the five varieties was higher than that at $0 \mathrm{~g} / \mathrm{L}$. At high concentrations of toxin ( 10 and $15 \mathrm{~g} / \mathrm{L}$ ), callus quality of the five varieties was significantly lower than that at 0 and $5 \mathrm{~g} / \mathrm{L}$. This indicated that low concentrations of toxin could improve the quality of wheat callus from mature embryos and high concentrations would have an inhibitory effect.

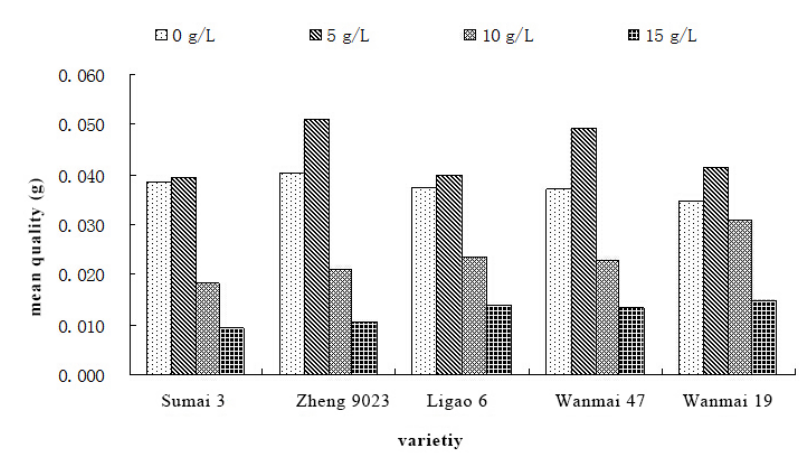

Figure 7. Effect of different concentrations of crude toxin on fresh weight of mature embryo callus.

\section{Effects of $F$. graminearum crude toxin on SOD activity in callus}

Under cultivation with $10 \mathrm{~g} / \mathrm{L}$ F. graminearum crude toxin, SOD activity of all five varieties was greater than that of the control group; With $20 \mathrm{~g} / \mathrm{L}$ toxin, SOD activity of the five varieties declined. The activities of Sumai 3 and Zheng 9023 were still higher than that of the control, while the other three varieties had lower activity compared to the control. As can be seen from Figure 8 , a consistent trend was observed in SOD activity of wheat callus of the five varieties, but SOD activity of Sumai3 was the highest, followed by medium-resistant Zheng 9023; the susceptible varieties Ligao 6, Wanmai 47 and Wanmai 19 had a lower SOD activity.

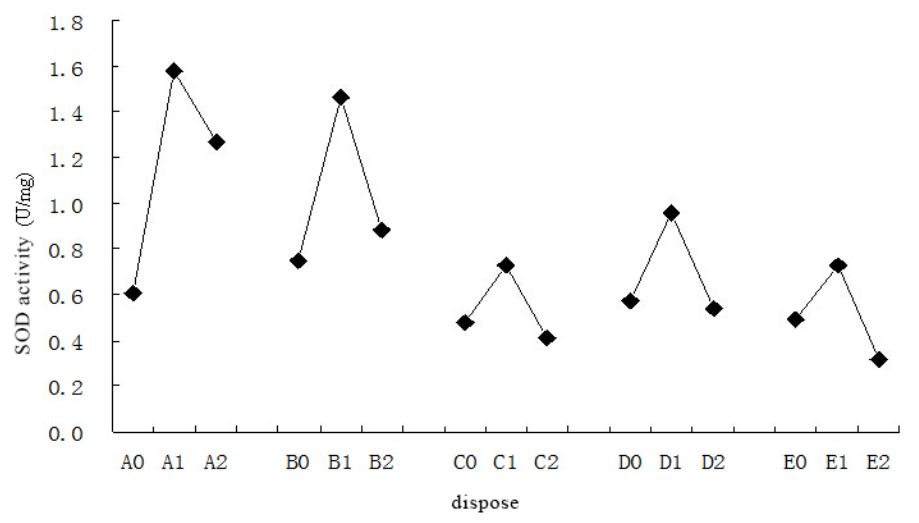

Figure 8. Effect of different concentrations of crude toxin on SOD activities of mature embryo callus. A: Sumai 3, B: Zheng 9023, C: Ligao 6, D: Wanmai 47, E: Wanmai 19, 0: 0 g/L, 1: 10 g/L, 2: 20 g/L. 
Increased SOD levels of mature embryo callus are shown in Figure 9. Sumai 3 had the highest increase in SOD activity, followed by Zheng 9023; that of Ligao 6 and Wanmai 19 was low.

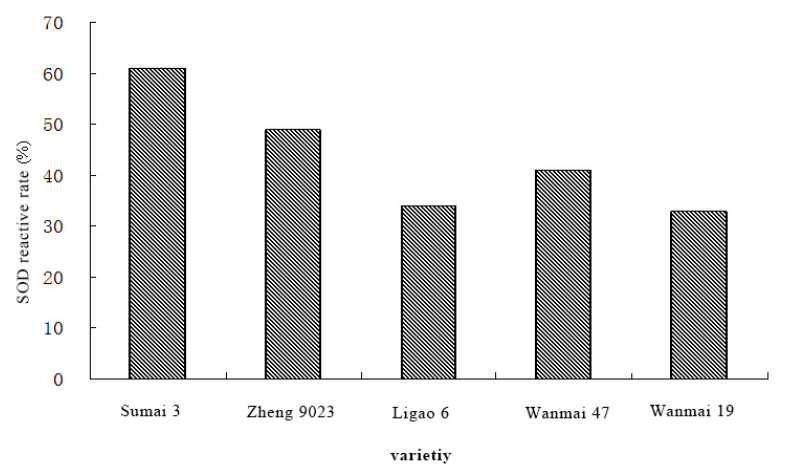

Figure 9. Effect of crude toxin on the increment ratios of SOD activity of different wheat varieties.

\section{DISCUSSION}

The efficient regeneration technology system for in vitro wheat culture is an important prerequisite for obtaining stress-induced mutants using F. graminearum crude toxin (Zhao et al., 1991). Appropriate concentrations of toxin and suitable genotypes are the key to successful in vitro screening (Lu et al., 1995). Wheat mature embryos were cultivated in vitro to obtain stress-induced mutants using F. graminearum crude toxin. The rate of callus induction and differentiation was similar to that of young spike and immature embryos (Wu et al., 1994; Yan et al., 1999; Duan et al., 2005; Zhang et al., 2006). Mature embryos are easy to get, and therefore, the establishment of mature embryos in an in vitro culture system stressed by F. graminearum crude toxin has opened the way for the screening of scab-resistant mutants by using somaclonal variation.

The study showed that low concentrations of $F$. graminearum crude toxin $(5 \mathrm{~g} / \mathrm{L})$ can promote the healing rate with strong resistance varieties, and increase the quality of callus. It indicated that low concentrations of $F$. graminearum crude toxin had a certain growth hormone activity. This feature is particularly evident for confrontational varieties. The results were consistent with previous studies (Liu et al., 1993; Chen et al., 1997). F. graminearum toxin showed different rates of mature embryo callus induction in different resistant varieties. It showed strong promotion for resistant varieties and significant inhibition for susceptible varieties. In differentiation culture, when the toxin concentration was $15 \mathrm{~g} / \mathrm{L}$, the susceptible cultivar callus rate was very low, where the rate was $2.86 \%$ for Ligao 6 and $1.43 \%$ for Wanmai 47 and 19 . Therefore, in the cell engineering technology system of stress-induced mutants by F. graminearum crude toxin, appropriate concentration of toxin should be selected to ensure the highest stress pressure and a certain degree of differentiation rate.

SOD is an important enzyme for scavenging free radicals in vivo. Generally, SOD activity was low. Under various stress conditions, SOD activity was increased, and resilience enhanced. The results showed that under the stress of $F$. graminearum crude toxin, the trends in SOD activity of five varieties of wheat callus from mature embryos increased at first, then decreased. SOD activity was highest at $10 \mathrm{~g} / \mathrm{L}$ toxin, while at $20 \mathrm{~g} / \mathrm{L}$, SOD activity decreased, indicating that low concentrations of the toxin can enhance SOD activity and that high concentrations of toxin may hamper SOD activity. SOD activity of mature embryo callus of Sumai 3, a resistant variety, 
increased the fastest, while that of susceptible varieties increased slowly; this was consistent with the findings of Guo et al. (2007). F. graminearum crude toxin rapidly stimulated the strong defense system (including SOD activity) of resistant varieties, which can prevent toxin from damaging the cell membrane and reduce membrane lipid peroxidation to some degree. At low concentrations of toxin, SOD activity of Zheng 9023, a medium-resistant variety, was slightly lower than that of the very resistant variety Sumai 3 , and significantly higher than that of susceptible varieties, indicating that it had a certain degree of defense function, while the susceptible varieties lacked such defenses. Therefore, there is a relationship between SOD activity and scab resistance of wheat varieties, which can be applied in the identification of resistant mutants.

\section{REFERENCES}

Chen YF, Li CL, Han DJ, et al. (1997). The Hormone-like Activity Toxin in Wheat of Fusarium Graminearum Tissue Culture. Acta Agric. Boreali-Occldentalis Sin. 6: 22-25.

Duan ZF, Zhu CQ and Zhu QL (2005). Effect of Fusarium Graminearum Croud Toxin on Calli in Wheat Young Embryos and Anthe Culture. Shandong Agric. Sci. 36-38.

Guo XM, Chen YF, Li CL, Ren HL, et al. (2007). Effects of Fusarium graminearum Crude Toxin on MDA Contents and SOD and PAL Activities in the Seedlings of Different Wheat Varieties. Acta Bot. Borea1-Occident. Sin. 27: 68-73.

Han QM, Cao LI and Kang ZS (2003). Research Progress on Fusarium Head Blight Toxin. J. Xi'an Unit. Univer. 6:18-21.

Liu SH, Wu SX, Guo YC, Kang SY, et al. (1997). Studies on Screening Somatic Cell Lines Resistant to Scab via Explant Culture of Wheat. J. Fujian Academy of Agric. Sci. 12: 7-10.

Liu XQ, LI X and Zhang XM (1999). The Relationship Between Resistance to Wheat Scab of Wheat Varieties and Resistance to Fusarium Graminearum Toxin. J. Huazhong Agric. Univer. 18: 416-418.

Liu ZZ, Lu SH, Huang XM, et al. (1993). Growth Hormone-like Activity of Deoxynivalenol Toxin and Fusarium Head Blight. Acta Agric. Shanghai 92-96.

Lu WZ, Jing N, Zhou N. (1995). Studies on Somaclonal Variation of Scab Resistant Lines in Wheat. J. Agric. Biotechnol. 3: 7-11. Lu WZ, Cheng SH and Wang YZ (2011). Study on Wheat Fusarium Head Blight. Science Press, Beijing.

Song FY, Li LF, Chen LJ, L SUN, et al. (2005). Progress of Wheat Improvement for Scab Resistance. Heilongjiang Agric. Sci. 41-44. Wang GJ (1999). Effect of Scab Toxin on Resistant and Susceptible Wheat Varieties. Acta Phytopathol. Sin. 29: 320-325.

Wu ZF and Wang YZ (1994). Selection of Wheat Mutants for Resistance to Crude Toxio Fusarium Graminearum. J. Jiangsu Agric. College 15: 35-39.

Yan B, Xue XZ and Chen JL (1995). Screening Scab Resistance Mutants Young Inflorescence Culture of Wheat. Acta Agric. Boreali-Occldentalis Sin. 4: 8-12.

Zhang XH, Chen YF, Min DH, et al. (2006). Effect of Fusarium Graminearum Croud Toxin and Embryo Development Time on Inducement and Plantlet Differentiation of Calli in Wheat Young Embryos Culture. J. Northwest Sci. Tech. Univ. Agri. For. 34: 92-96.

Zhang ZL and Zhai WQ (2003). Experimental instruction of Plant physiology. Beijing: Higher education Press.

Zhao CZ (1991). Application of Somaclonal Variation in Cereal Crops. Shanghai Science and Technology Press, Shanghai, 91-101. 